\title{
Lender Characteristics and the Neurological Reasons for Strategic Mortgage Default
}

Authors Michael J. Seiler and Eric Walden
Abstract

An economic mortgage default is said to have occurred when a borrower can no longer afford to pay his mortgage. ${ }^{1}$ A strategic mortgage default is when the borrower can afford to continue making payments, but for one reason or another decides not to. Wyman (2010) and Guiso, Sapienza, and Zingales (2013) document that strategic mortgage defaults are on the rise, and FICO (2011) explains that strategic default is a major inhibitor to a recovery of the housing market. Moreover, traditional mortgage models are not equipped to identify/counteract this exercising of a homeowner's put option. As a result, there is a great need in the industry to stem the tide of strategic default incidences.

Seiler (2014) references the ultimatum game literature and uses inequity aversion theory to explain how borrowers are willing to put themselves in financial harm's way to seek retribution against lenders who follow unfair lending practices and/ or who have received government bailout funds. He elucidates a number of flaws in the logic process of homeowners who are willing to sacrifice their personal wealth, credit score, and so forth, in order to penalize wrongdoing lenders.

For example, Seiler (2014) finds that borrowers dramatically over-estimate the number of lenders that have engaged in egregious lending practices. Moreover, 
borrowers do not have a good understanding whatsoever of which lenders did and did not receive government bailout funds. ${ }^{2}$ Worse yet, the borrowers did not have any idea whether or not their lenders engaged in egregious behavior. Even if they did, he documents the rampant inability of borrowers to differentiate between the servicer of the loan and the underlying owner. This is the most troubling aspect of the study's findings because it implies that if borrowers decide to seek retribution on a lender who they perceive to have behaved egregiously, they will take out their disdain on the wrong institution. ${ }^{3}$ Misunderstandings of lenders' past behavior coupled with a willingness to seek retribution might well result in a continued downturn in the market and a prolonged economic recession.

Until we better understand what borrowers are thinking and feeling, it is difficult to construct housing policies aimed at effectively counteracting their willingness to seek retribution against their lender through a strategic mortgage default. The purpose of this study is to do exactly this. We use functional magnetic resonance imaging (fMRI) technology to infer what borrowers are feeling in real time as they contemplate strategic mortgage default decisions. Through a controlled environment, this neurological approach allows us to match areas of brain activity with specific aspects of the strategic default decision. This approach also allows us to compare the responses we get through a traditional survey approach (where borrowers share their stated preference) with the revealed preferences that are observed from a neurological examination. ${ }^{4}$

We first examine trials where borrowers are turned down for a loan modification. We compare their willingness to strategically default on loans originated through egregious lenders versus those made through financially conservative lenders. Based on significantly differential activation in the frontal poles bilaterally, cerebellum, and left angular gyrus, we conclude that borrowers are trying to restrain themselves against an action they can see themselves taking in the future. Alternatively stated, borrowers want to lash out against the lender, but are struggling to restrain themselves.

We next examine pairs of trails that differ between origination through online lenders (whose names they do not recognize) versus origination through a local lender with whom they have a long-term relationship. Significant activation is found in the inferior frontal gyrus, leading us to conclude that borrowers are working hard to inhibit a negative response when considering strategic default on a local lender. Finally, we compare an environment where strategic defaults are rare versus when they are common. Based on activation in the pre-motor cortex bilaterally and the right insular cortex, we conclude that when mortgage defaults are rare, defaulting by the borrower violates the social norm causing feelings of disgust. The fear of being the only one who stands alone is well documented in economics (Keynes, 1965) and has been the finding of several recent strategic default foreclosure contagion studies (e.g., Rogers and Winter, 2009; Daneshvary, Clauretie, and Kader, 2011; Ding, Quercia, Li, and Ratcliffe, 2011; An and Qi, 2012; Gangel, Seiler, and Collins, 2013; and Seiler, Lane, and Harrison, 2014). 
In collocating trials where a loan modification was refused versus those in which a modification was granted, we document heightened brain activity in the premotor cortex, lingual gyrus bilaterally, and a portion of the inferior temporal gyrus, which is consistent with people who are seeking retribution (to the lenders who refused to modify their loans). Finally, we learn that granting a loan modification largely cancels out the effect of changing the social norm to make strategic defaults common. Thus, for banks who have engaged in egregious lending practices, granting even a modest loan modification can reduce the inclination to strategically default to a level consistent with a financially conservative local bank with which the borrower has a long-term relationship. This powerful result indicates the ease with which a lender can repair a broken relationship with the public simply by sending the signal of cooperation moving forward.

Finally, when simply comparing trials where the borrower indicated a greater willingness to default, we observe differentially significant activation in the superior frontal gyrus (an executive area that deals with uncertainty), the anterior cingulate gyrus (monitoring and error checking), the posterior cingulated gyrus and the thalamus (limbic regions involved with emotional processing), and the pre-motor cortex (planning actions). Taken together, the results reveal that as borrowers become increasingly willing to strategically default, they also become more emotionally charged, uncertain, and alert for errors in their judgment. In short, they are thinking more about this important decision on both an emotional and economic level.

\section{Dataset}

While most studies in the field of neuroscience use students as a convenience sample, we argue that it is far better to use actual homeowners with an existing mortgage when studying the impacts of lender characteristics on strategic default decisions (Seiler, Collins, and Fefferman, 2013). For this reason, we placed an advertisement in the local newspaper for homeowners to participate in a study of the housing market. We specifically did not convey the precise purpose of our study to avoid sample selection bias..$^{5}$ Borrowers willing to take time from their day to visit our laboratory and be part of our study were paid a $\$ 25$ participation fee. In all, there are 20 homeowners in our sample who each considered 60 lender characteristic conditions. The result is a participant-trial sample size of 1,200 observations. Desmond and Glover (2002), Zandbelt et al. (2008), and Dimoka (2012) support the use of as few as 12 participants for an fMRI study using our parameters. $^{6}$

Overall, our sample of participant homeowners is consistent with the national profile reported in the American Housing Survey (AHS) and American Community Survey (ACS). Our homeowner ethnic make-up is $62.5 \%$ Caucasian, $60 \%$ married, $55 \%$ with children, $50 \%$ with a college degree, and 44.9 years of 
age. AHS/ACS figures are 79.1\% Caucasian, 52.3\% married, 66.2\% with children, $33.8 \%$ with a college degree, and 52 years old.

\section{Experimental Design}

Subjects were given a hypothetical loan with the following parameters: ${ }^{7}$ Purchase price is $\$ 240,000$; down payment equals $\$ 20,000$; outstanding loan balance is $\$ 210,000 ;{ }^{8}$ a current market price of $\$ 110,000$; and a (negative) equity position of $-\$ 100,000 .{ }^{9}$ The subjects are next provided with additional details relating to the circumstances surrounding the loan. ${ }^{10}$ For example, they are told that they have requested a loan modification and whether or not that modification has been granted. They are also told of the general character of the lender and the nature of the foreclosure environment. These considerations fall into one of three paired categories: (1) the lender is financially conservative versus the lender has engaged in egregious behavior; (2) the lender is a local bank versus the lender is an online institution; or (3) defaults are common versus defaults are rare.

The subject is then walked through a total of 60 uniquely worded trials that are purposefully balanced so that five of each of the conditions is paired with a denied modification request and five are paired with a granted request. Some examples are displayed in Exhibit 1. A sample image of the screen appears in Exhibit 2.

The experimental task required subjects to indicate how likely he/she is to strategically default on a mortgage under each of the 60 lender characteristic condition trials. Strategic mortgage default likelihood was presented on a 9-point scale from highly likely (1) to highly unlikely to strategically default (9). Participants were allowed 14 seconds to provide a strategic default proclivity in each trail. Once the 14 seconds elapsed, the screen was replaced with a fixation cross that lasted two seconds before another trial was provided. The reason for the two second delay is to allow blood flow to return to a neutral area of the brain. Effectively, the brain is allowed to reset itself in between trials. The aggregate time to complete all 60 trials is 16 minutes. $^{11}$

\section{Experimental Results}

Before we examine the central contribution of this study, namely the use of fMRI technology to uncover the hidden mental considerations when borrowers contemplate strategic mortgage default, we first explore traditional experimental results similar to those tested in Seiler (2014). Panel A of Exhibit 3 reports the willingness to strategically default when the lender does versus does not grant a loan modification. Not surprisingly, the borrower's willingness to default is significantly different between these two alternatives. In Panel B, the central hypothesis of Seiler (2014) is supported by observing that each of the three pairs of lender characteristics/market conditions are associated with significantly different strategic default proclivity rates. 
Exhibit 1 | Sample of Lender Characteristic Differences and Modification Outcomes

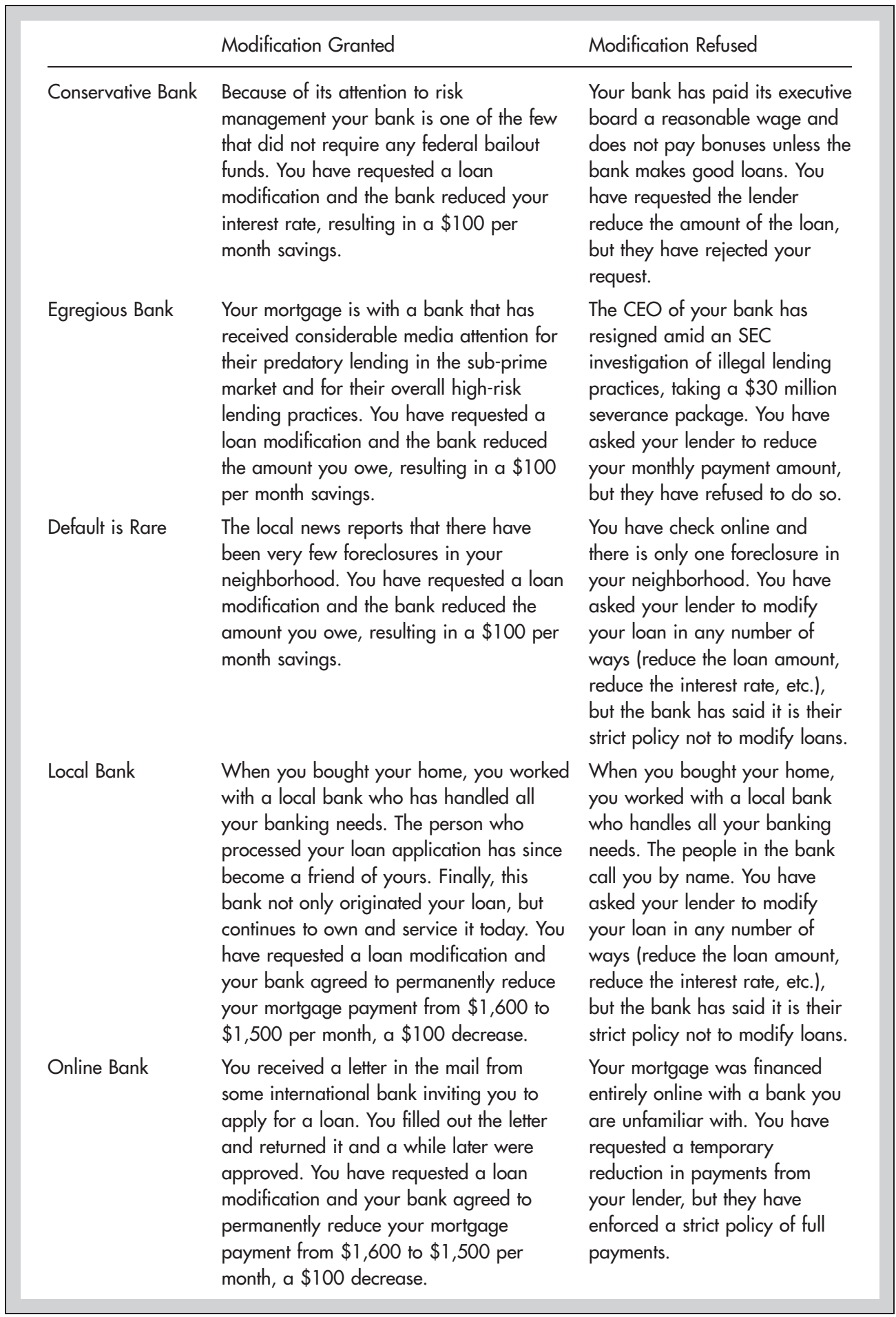


Exhibit 1 | (continued)

Sample of Lender Characteristic Differences and Modification Outcomes

\begin{tabular}{|c|c|c|}
\hline & Modification Granted & Modification Refused \\
\hline Default is Common & $\begin{array}{l}\text { A realtor friend of yours has told you that } \\
\text { foreclosures in your area have been high } \\
\text { lately. You have requested a loan } \\
\text { modification and the bank reduced your } \\
\text { interest rate, resulting in a } \$ 100 \text { per } \\
\text { month savings. }\end{array}$ & $\begin{array}{l}\text { The local newspaper has } \\
\text { reported that almost } 1 \text { in } 5 \\
\text { homes are in default locally. } \\
\text { You have requested the lender } \\
\text { reduce the amount of the loan, } \\
\text { but they have rejected your } \\
\text { request. }\end{array}$ \\
\hline \multicolumn{3}{|c|}{$\begin{array}{l}\text { Notes: This exhibit shares a sample of the } 60 \text { unique trials that differ by four lender } \\
\text { characteristics, two different default environments, and three various loan modification request } \\
\text { outcomes. Each subject receives five trails from each of the } 12 \text { cells in a random order with } \\
\text { random parings between the modification and the character of the lender. }\end{array}$} \\
\hline
\end{tabular}

Comparing Panel $\mathrm{C}$ to Panels D, E, and F in Exhibit 3, we observe that when a lender modifies a loan (using any method) the borrower's stated willingness to seek retribution in all three pairs is removed. The similarity in results across the three substantially different samples ${ }^{12}$ [two from Seiler (2014); one used in the current investigation] indicate that the core findings of both studies can reasonably be generalized to other areas and subsamples of homeowners.

fMRI Results

\section{Egregious versus Conservative Lender Trials}

Egregious lenders produced greater activation than conservative lenders through activation in the frontal poles bilaterally, as shown in Exhibit $4 .{ }^{13}$ This area is known to be activated when subjects try to inhibit a response (Liddle, Kiehl, and Smith, 2001), particularly a stereotypical response (Kadota et al., 2010). Simply stated, this area of the brain is activated when people fight against knee-jerk reactions. Greater activation in this area for egregious lenders reveals that people have a reaction to these banks on which they try not to act. This is a good example of an emotional consideration being muted by a person who is rationally concerned about the ramifications of making decisions based on emotion.

The egregious lenders also produce greater activation in the cerebellum and left angular gyrus. These areas have both been found to be part of a network that is 
Exhibit 2 | Screen Capture of a Typical Trial Seen by the Borrower

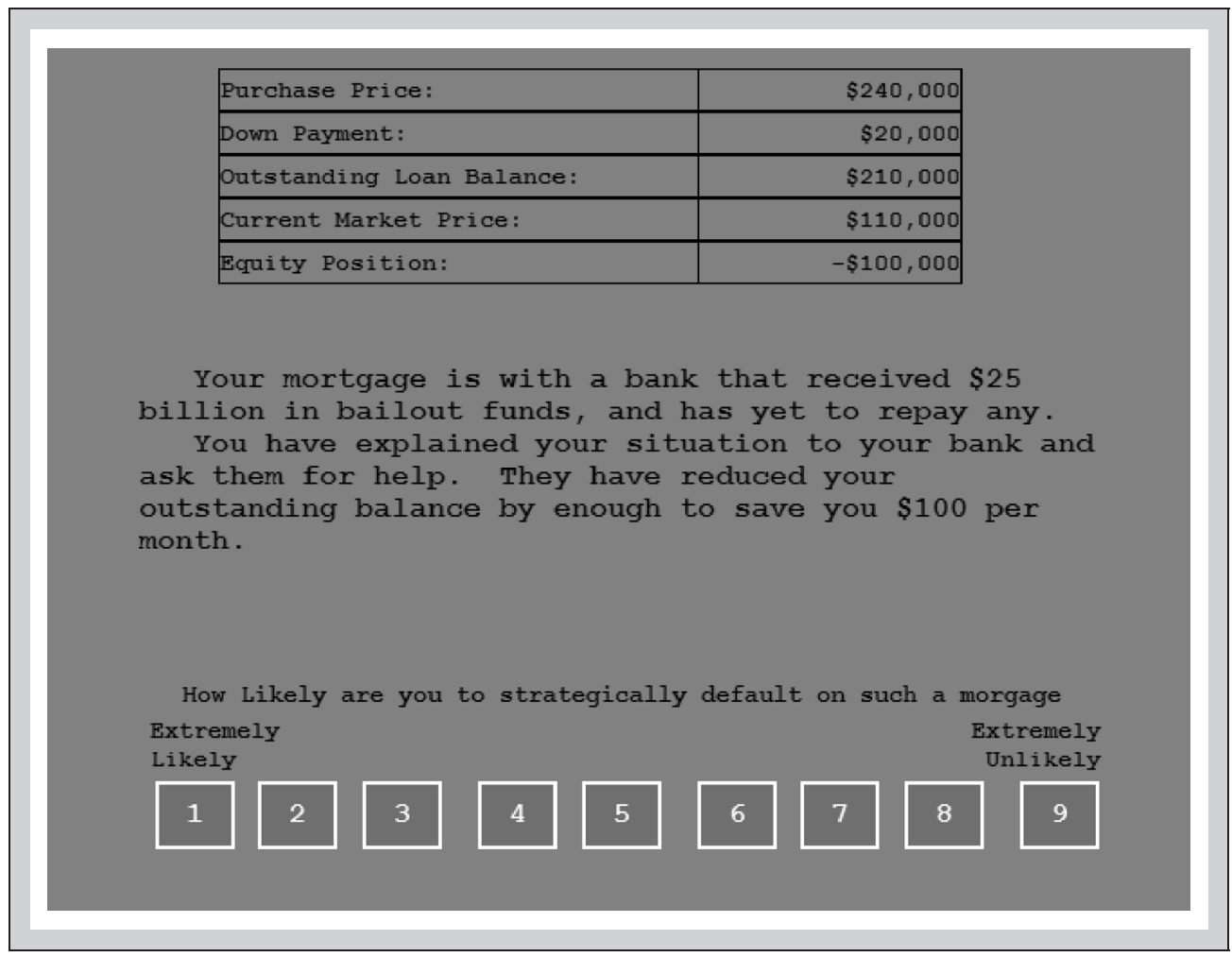

Notes: This exhibit reveals the typical screen a borrower sees in a typical trial. The first part describes the character of the lender, while the second part shares the outcome of the loan modification request.

preferentially activated when one contemplates future actions (Viard et al., 2011). Combined, these findings indicate that subjects are trying to inhibit an action they are imaging themselves taking. Alternatively stated, borrowers instinctively want to lash out against egregious lenders, but are trying not to. Presumably, they are trying to inhibit this response out of a sense of responsibility to repay the loan or out of an unwillingness to do something considered socially undesirable.

While the decision is currently being kept in check, this ticking time bomb could be very bad for lenders as it has been shown that disruption of these areas leads people to be worse at inhibition (Kadota et al., 2010). In a laboratory setting, transcranial magnetic stimulation has been used to temporarily disrupt this area. In the real world, stress, fatigue, or excessive frustration can also disrupt specific brain functions. Consistent with Seiler (2014), this result shows that if lenders can rebuild a good faith relationship with borrowers, they could potentially remove the need for people to inhibit the behavior they actually want to exhibit. 
Exhibit 3 | Homeowner Strategic Default Measures by Modification and Bank Type

\begin{tabular}{|c|c|c|c|c|c|}
\hline Variable & Obs. & $\begin{array}{l}\text { Mean } \\
\text { Strategic } \\
\text { Default } \\
\text { Willingness }\end{array}$ & $\begin{array}{l}\text { Independent } \\
\text { Samples } \\
T \text {-Test } \\
p \text {-value }\end{array}$ & $\begin{array}{l}\text { ANOVA } \\
\text { ( } p \text {-value) }\end{array}$ & $\begin{array}{l}\text { Post-Hoc } \\
\text { Significant } \\
\text { Pairs } \\
\text { (p-value) }\end{array}$ \\
\hline & 1178 & 5.32 & & & \\
\hline \multicolumn{6}{|l|}{ Panel A: Modification type } \\
\hline No Modification & 589 & 4.27 & $0.000^{* * *}$ & & \\
\hline Modification & 589 & 6.37 & & & \\
\hline Interest Rate Reduction & 237 & 6.30 & & 2.37 & (2) \& (3) \\
\hline Principal Reduction & 235 & 6.60 & & $(0.095)^{*}$ & $(0.035)^{* *}$ \\
\hline General Payment Reduction & 117 & 6.03 & & & \\
\hline
\end{tabular}

Panel B: All cases

\begin{tabular}{llll}
\hline Local Bank & 194 & 5.77 & $0.005^{* * *}$ \\
Online Bank & 197 & 5.01 & \\
Conservative Bank & 199 & 5.81 & $0.000^{* * *}$ \\
Egregious Bank & 194 & 4.41 & \\
Defaults are Rare & 196 & 5.94 & $0.000^{* * *}$ \\
Defaults are Common & 198 & 4.97 & \\
\hline
\end{tabular}

Panel C: No modification

\begin{tabular}{lrrr}
\hline Local Bank & 95 & 4.73 & $0.020^{* *}$ \\
Online Bank & 99 & 3.85 & \\
Conservative Bank & 99 & 4.83 & $0.000^{* * *}$ \\
Egregious Bank & 100 & 3.40 & \\
Defaults are Rare & 98 & 4.92 & $0.011^{* *}$ \\
Defaults are Common & 98 & 3.95 & \\
\hline
\end{tabular}

Panel D: Interest rate modification

\begin{tabular}{llll}
\hline Local Bank & 40 & 6.70 & 0.464 \\
Online Bank & 39 & 6.31 & \\
Conservative Bank & 40 & 6.63 & $0.036^{* *}$ \\
Egregious Bank & 38 & 5.45 & \\
Defaults are Rare & 40 & 7.00 & $0.015^{* *}$ \\
Defaults are Common & 40 & 5.70 &
\end{tabular}


Exhibit 3 | (continued)

Homeowner Strategic Default Measures by Modification and Bank Type

\begin{tabular}{|c|c|c|c|c|c|}
\hline \multirow[t]{2}{*}{ Variable } & Obs. & $\begin{array}{l}\text { Mean } \\
\text { Strategic } \\
\text { Default } \\
\text { Willingness }\end{array}$ & $\begin{array}{l}\text { Independent } \\
\text { Samples } \\
T \text {-Test } \\
p \text {-value }\end{array}$ & $\begin{array}{l}\text { ANOVA } \\
\text { ( } p \text {-value) }\end{array}$ & $\begin{array}{l}\text { Post-Hoc } \\
\text { Significant } \\
\text { Pairs } \\
\text { ( } p \text {-value) }\end{array}$ \\
\hline & 1178 & 5.31 & & & \\
\hline \multicolumn{6}{|c|}{ Panel E: Principal reduction modification } \\
\hline Local Bank & 40 & 7.05 & 0.163 & & \\
\hline Online Bank & 39 & 6.38 & & & \\
\hline Conservative Bank & 40 & 7.15 & $0.007^{* * *}$ & & \\
\hline Egregious Bank & 37 & 5.73 & & & \\
\hline Defaults are Rare & 39 & 6.97 & 0.139 & & \\
\hline Defaults are Common & 40 & 6.23 & & & \\
\hline \multicolumn{6}{|c|}{ Panel F: General payment reduction modification } \\
\hline Local Bank & 19 & 6.37 & 0.299 & & \\
\hline Online Bank & 20 & 5.55 & & & \\
\hline Conservative Bank & 20 & 6.35 & 0.124 & & \\
\hline Egregious Bank & 19 & 5.05 & & & \\
\hline Defaults are Rare & 19 & 6.89 & 0.239 & & \\
\hline Defaults are Common & 20 & 6.00 & & & \\
\hline \multicolumn{6}{|c|}{$\begin{array}{l}\text { Notes: This exhibit shows summary results for all variations of the experiment. The sample size, } \\
\text { mean willingness to strategically default, as well as statistical significance testing is provided. Panel } \\
\text { A reports the results by modification type. Panel B shows results for all bank types in all trials, } \\
\text { while Panels C through F report disaggregated results segmented by modification type. The total } \\
\text { sample size is } 1,178 \text {. Asterisks indicate statistical significance between grouped rows based on } \\
\text { ANOVA/ Post Hoc Tests (Panel A) and Independent-Samples } t \text {-tests (Panels B F). } \\
{ }^{*} \text { Significant at the } 10 \% \text { level. } \\
{ }^{* *} \text { Significant at the } 5 \% \text { level. } \\
{ }^{* * *} \text { Significant at the } 1 \% \text { level. }\end{array}$} \\
\hline
\end{tabular}

\section{Online versus Local Lender Trials}

As shown in Part A of Exhibit 5, local lenders produced a single area of greater activation when compared to online lenders in the inferior frontal gyrus, an area associated with response inhibition (Hampshire et al., 2010). It would appear then that subjects are working harder to inhibit responses when they are faced with a 
Exhibit 4 | FMRI Results for Egregious versus Conservative Lender Trials

\section{Panel A: Two-Dimensional Imagery}

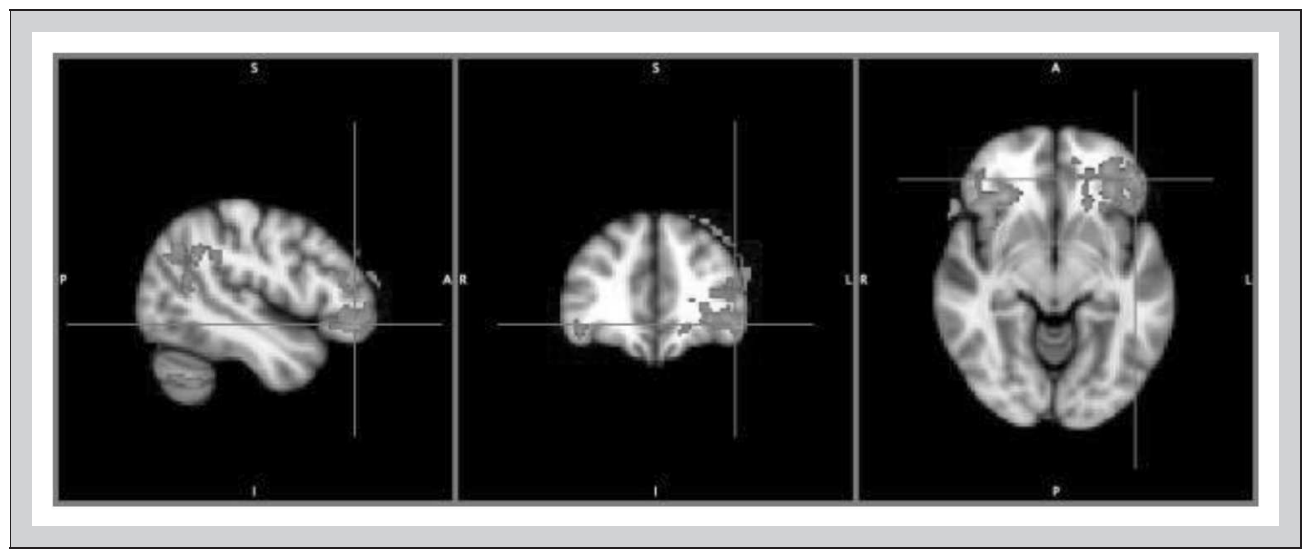

\section{Panel B: Three-Dimensional Imagery}

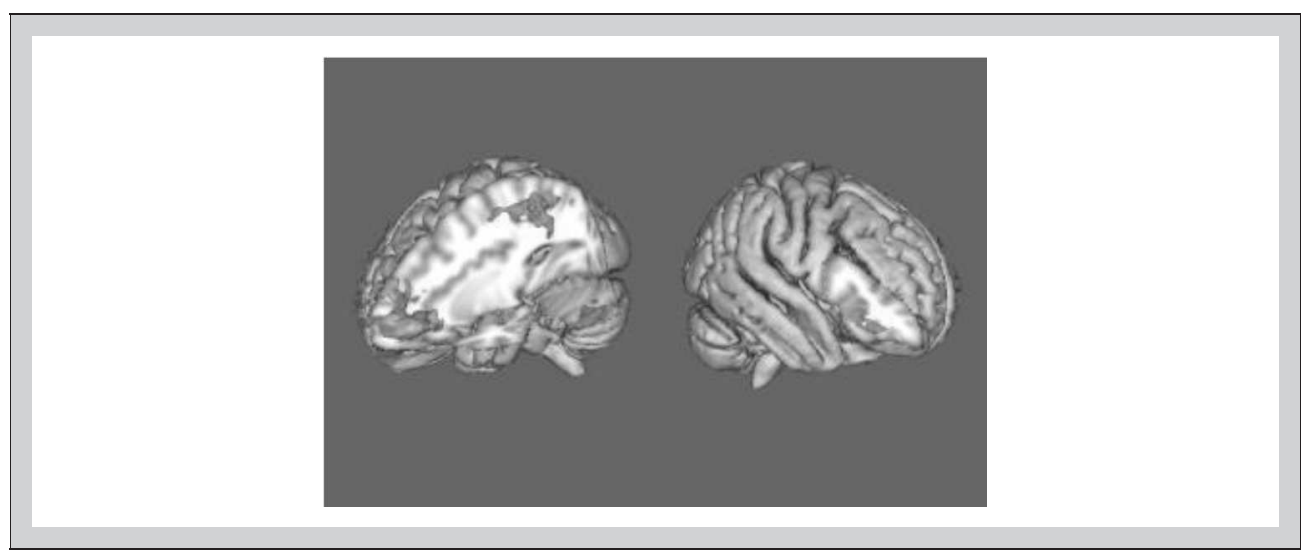

Notes: This exhibit shows fMRI brain scan images for significant substrate brain activation when comparing egregious to financial conservative lender trials. Three significantly differential activation areas include the frontal poles bilaterally [activated when subjects try to inhibit a (stereotypical) response], and the cerebellum and left angular gyrus (activated when one contemplates future actions).

local bank. When reversing the vantage point, online lenders produced a single cluster of greater activation than local banks, as shown in Part B of Exhibit 5. This cluster is located mainly in the left superior frontal gyrus, an area associated with working memory (Boisgueheneuc et al., 2006). This area is particularly attuned to spatial memory. As such, we attribute this activation to the borrower thinking geospatially about the physical location (near vs. far) of each type of lender. Otherwise, no significantly differential activation was observed. 
Exhibit 5 | fMRI Results for Online versus Local Lender Trials

\section{Panel A: Local Lender Trials minus Online Lender Trials}

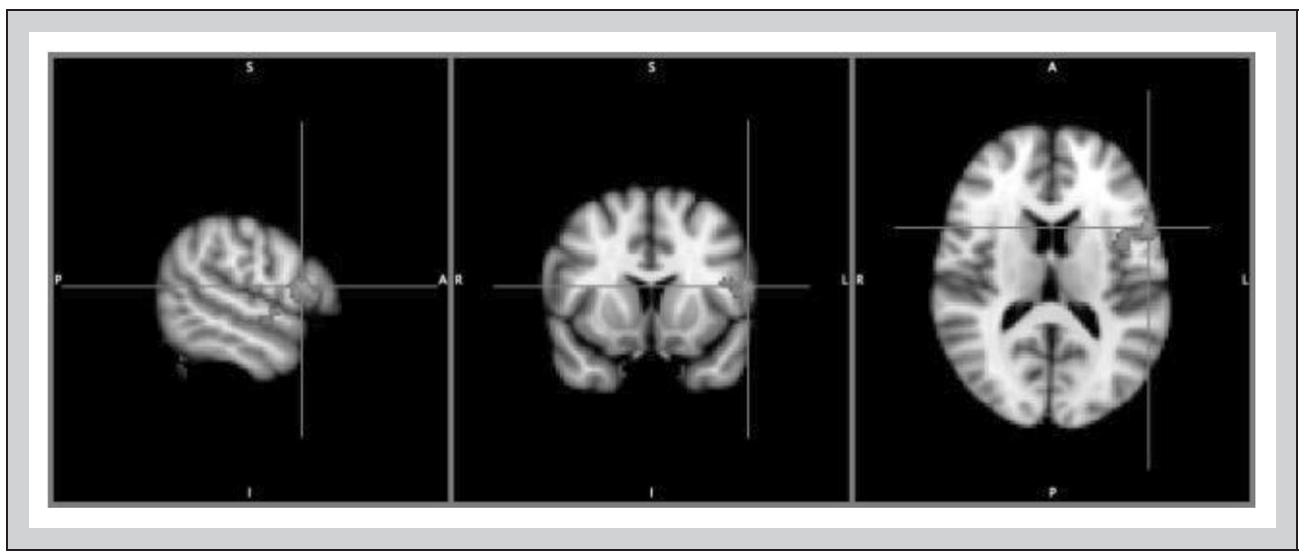

Panel B: Online Lender Trials minus Local Lender Trials

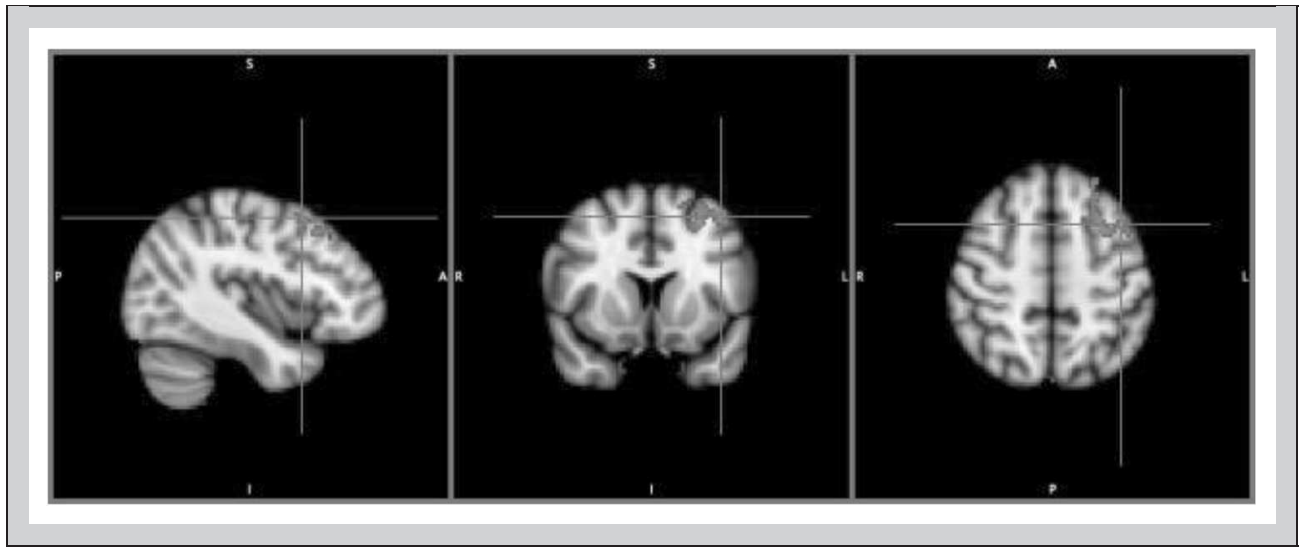

Notes: This exhibit shows fMRI brain scan images for significant substrate brain activation when comparing online versus local lender trials. In Panel A, the online lender is subtracted from local lender trials, while in Panel B, the local lender is subtracted from online lender trials. In Panel A, a single significantly differential activation area involves the inferior frontal gyrus (an area associated with response inhibition). In Panel B, a single significantly differential activation area involves the left superior frontal gyrus (an area associated with working memory).

Rareversus Common Default Trials

As seen in Exhibit 6, there are two clusters where rare defaults cause greater activation than common defaults. These include the pre-motor cortex bilaterally and the right insular cortex. The pre-motor cortex is involved in many types of reasoning, but is especially necessary for planning future actions. The insular 
Exhibit 6 | fMRI Results for Rare versus Common Default Trials

Panel A: Two-Dimensional Imagery

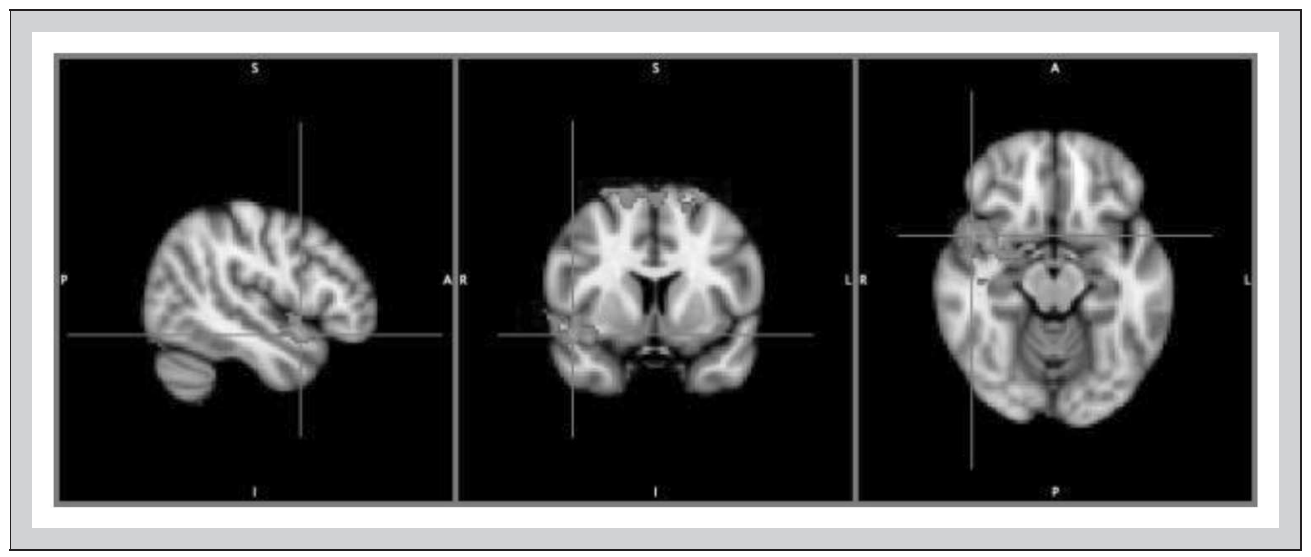

Panel B: Three-Dimensional Imagery

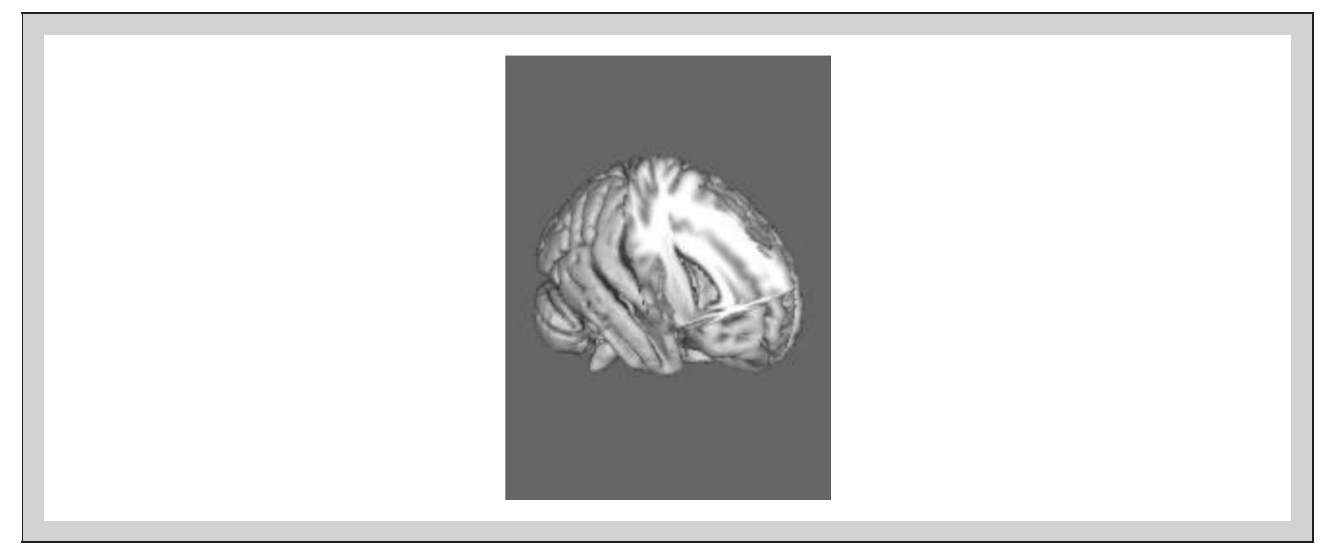

Notes: This exhibit shows fMRI brain scan images for significant substrate brain activation when comparing trials in which strategic defaults are rare versus when they are common. Two significantly differential activation areas include the pre-motor cortex bilaterally (activated when planning future actions), and the right insular cortex (activated when one experiences feelings of disgust).

cortex is associated with feelings of disgust (Wicker et al., 2003; Jabbi, Bastiaansen, and Keysers, 2008). Taken together, this indicates that when subjects consider default in an environment where others do not default, they experience a more visceral reaction. More specifically, when they think about how they will respond to the question, "How likely are you to strategically default?," they appear to feel more disgust with their planned actions. It makes sense that if someone contemplates themselves taking an action that violates the social norm, they will experience a disgust-like sensation. ${ }^{14}$ 
Exhibit 7 | FMRI Results for Modification Refusals versus Modification Granting

\section{Panel A: Two-Dimensional Imagery}

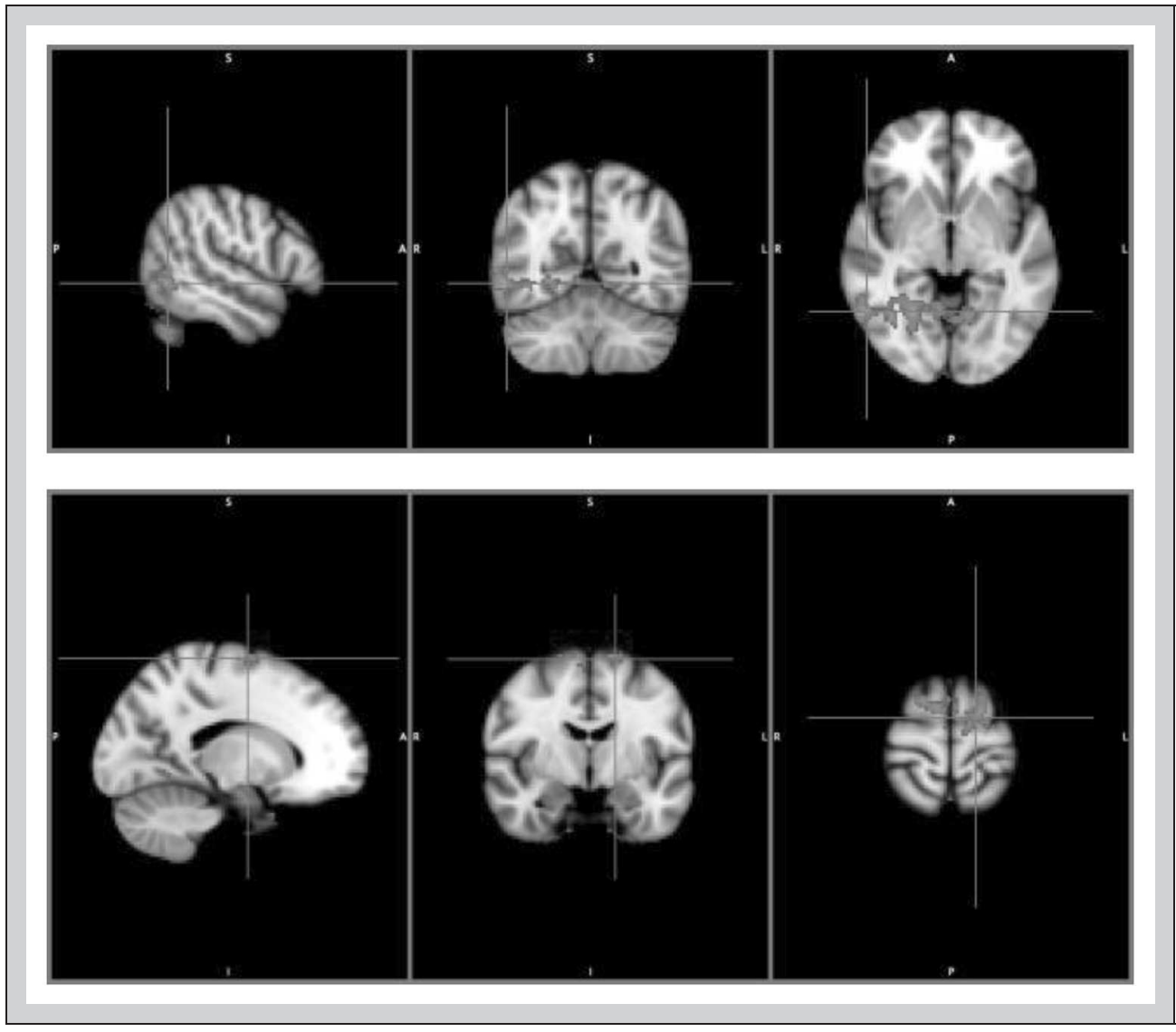

Refused versus Granted Loan Modification Trials

When borrowers are told that the lender refused their request to modify a loan, they exhibit three clusters of increased activation relative to when the lender acquiesces to the modification request (see Exhibit 7). These include the lingual gyrus bilaterally, the pre-motor cortex, and a portion of the inferior temporal gyrus. The lingual gyrus is associated with autobiographical thinking, the pre-motor cortex is associated with the planning of action, and the inferior temporal gyrus is associated with theory of mind processing (Völlm et al., 2006). This implies that subjects are trying to inhibit the (presumably negative) actions they would like to take in response to the refusal of the lender to modify the loan. More directly, these activations are consistent with people thinking of retribution. 


\section{Exhibit $\mathbf{7}$ | (continued) \\ fMRI Results for Modification Refusals versus Modification Granting}

\section{Panel B: Three-Dimensional Imagery}

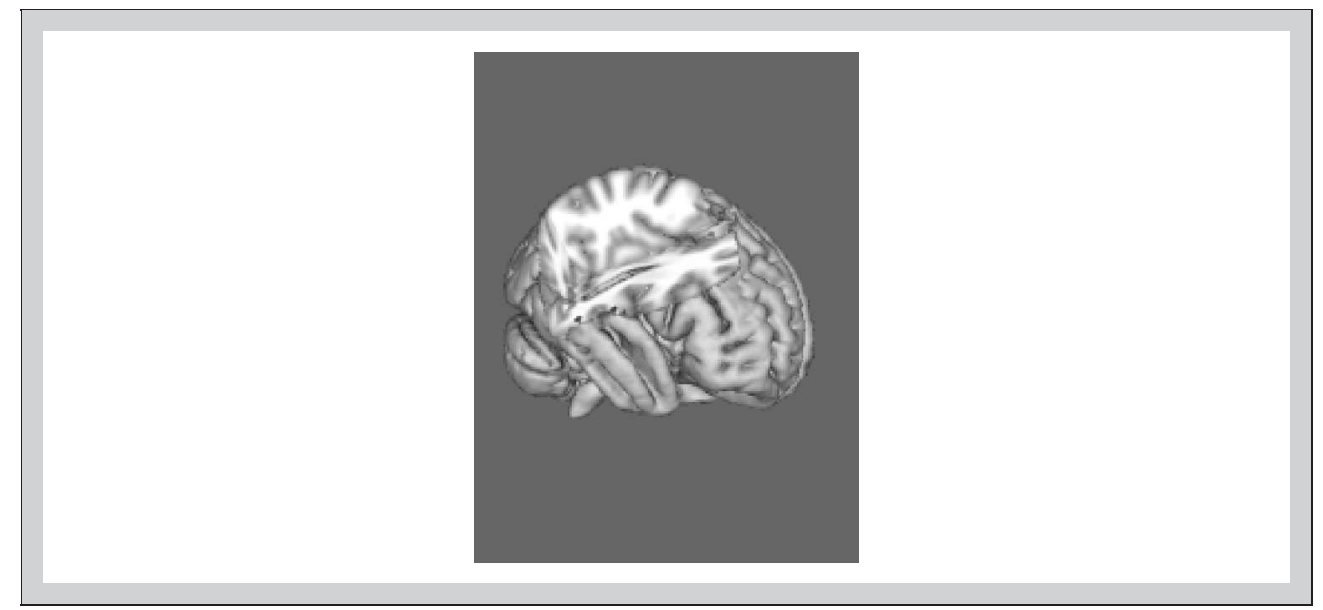

Notes: This exhibit shows FMRI brain scan images for significant substrate brain activation when comparing trials in which modifications were refused versus when modifications were granted. Three significantly differential activation areas include the lingual gyrus bilaterally (associated with autobiographical thinking), the pre-motor cortex (activated when planning future actions), and a portion of the inferior temporal gyrus (associated with the theory of mind processingl.

\section{Interaction Effect Trials}

There was only one interaction of modification outcome and lender characteristics that revealed any significant clusters of activation. As seen in Exhibit 8, when a modification was granted in a situation where default was common, there was greater activation in several areas than when a modification was granted and default was rare. These areas include the right lingual gyrus, pre-motor cortex, right insular cortex, and the right inferior temporal gyrus. These areas are very similar to the areas activated when default was rare plus the areas activated when modifications were refused. It seems when the social norm dictates that default is acceptable, but the lender actually works with the borrower by granting a loan modification, the borrower thinks much harder about his own decision whether or not to default. Alternatively stated, granting a loan modification largely cancels out the effect of changing the social norm to make default common. That is, we find that lenders can reduce the proclivity of borrowers to strategically default simply by sending a signal of cooperation.

\section{Increasing Willingness to Default}

In trials where subjects indicated they were more willing to default, there were several areas within the brain that showed increased activation, as shown in Exhibit 
Exhibit 8 | FMRI Results for Common Default versus Rare Default in Trials where Modification was Granted

\section{Panel A: Two-Dimensional Imagery}

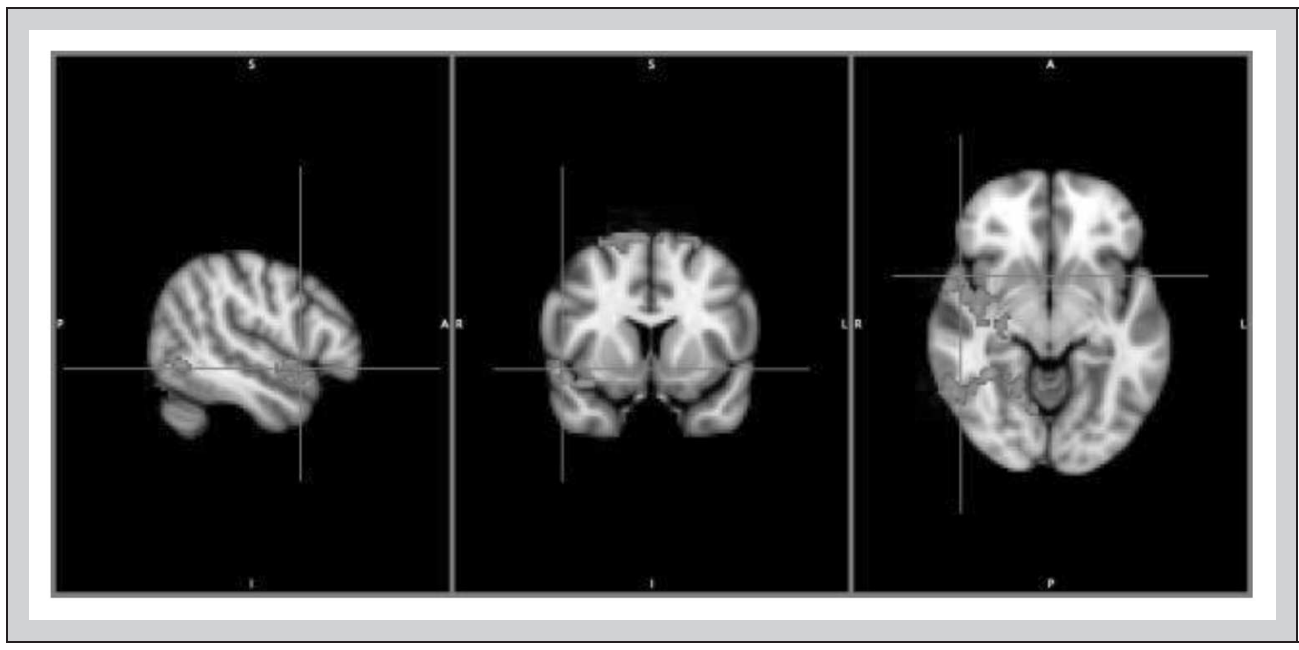

Panel B: Three-Dimensional Imagery

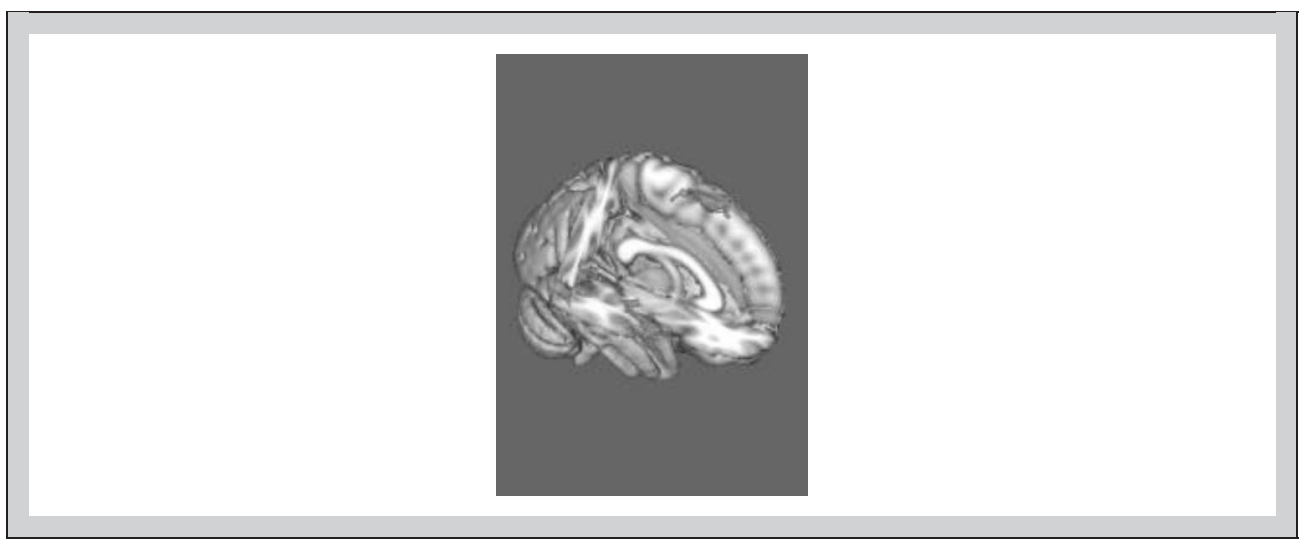

Notes: This exhibit shows fMRI brain scan images for significant substrate brain activation when comparing common default versus rare default trials interacted when loan modifications were granted. Significantly differential activation areas include the right lingual gyrus (associated with autobiographical thinking), the pre-motor cortex (activated when planning future actions), the right insular cortex (activated when one experiences feelings of disgust), and the right inferior temporal gyrus (associated with the theory of mind processing).

9. These areas include the superior frontal gyrus, the anterior and posterior cingulate gyrus, the thalamus, and the pre-motor cortex. The superior frontal gyrus is an executive area that deals with uncertainty, while the anterior cingulate deals with monitoring and error checking. The posterior cingulate and thalamus are both limbic regions involved with emotional processing. Finally, the pre-motor cortex

\begin{tabular}{l|l|lll} 
JRER & $\mathrm{V} \circ \mathrm{I} .36$ & $\mathrm{~N} \circ .3-2014$ \\
\hline
\end{tabular}


Exhibit 9 | FMRI Results for Greater Willingness to Strategically Default

\section{Panel A: Two-Dimensional Imagery}

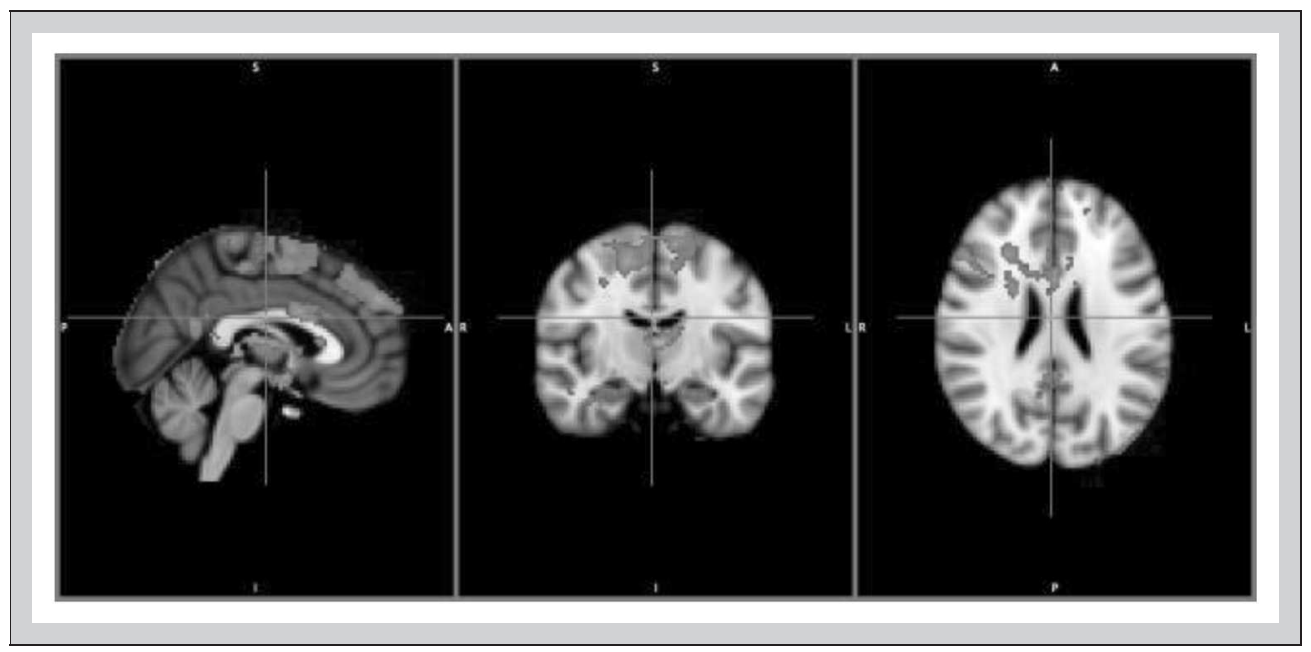

Panel B: Three-Dimensional Imagery

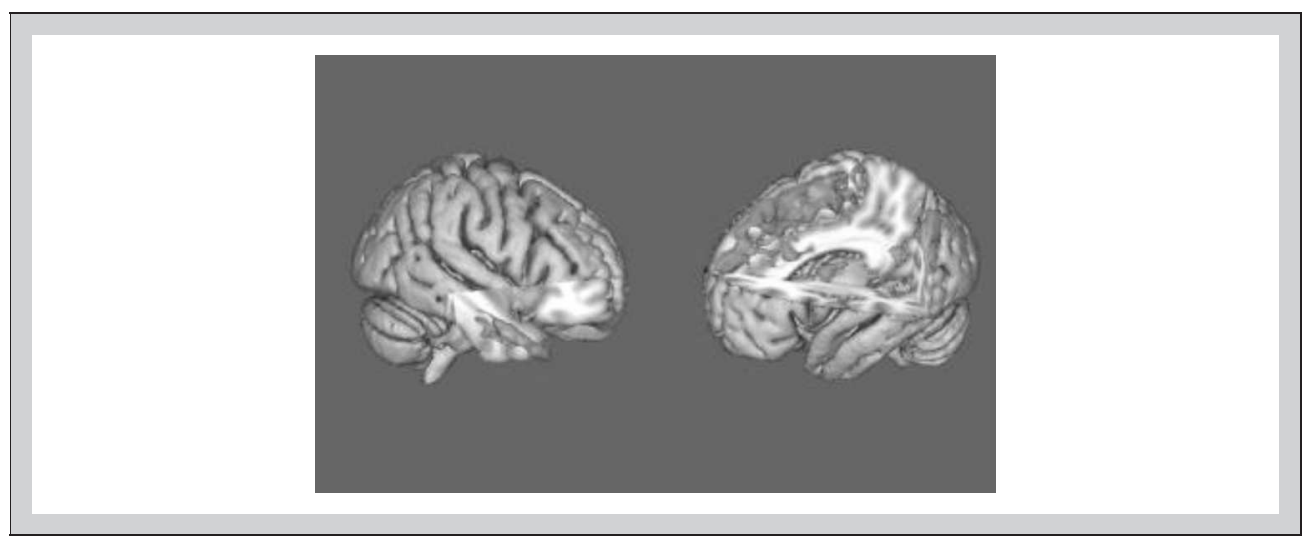

Notes: This exhibit shows fMRI brain scan images for significant substrate brain activation when subjects indicated a greater willingness to strategically default. Significantly differential activation areas include the superior frontal gyrus (an executive area used when dealing with uncertainty), the anterior cingulate gyrus (associated with monitoring and error checking), the posterior cingulate gyrus and thalamus (limbic regions involved with emotional processing), and the pre-motor cortex (activated when planning future actions).

plans action. Taken together, the results show that as people become more willing to strategically default, they become more emotionally charged, uncertain, and alert for errors in their judgment. They are thinking more about this important decision on both an emotional and factual level. It is clear that subjects did not enter into this judgment lightly. 


\section{Conclusion}

Overall, the findings indicate that inhibition plays a large role in strategic default. Intuitively, this makes sense. By definition, strategic default feels good for the defaulter (at least in the first approximation), and it is a natural proclivity of the brain to make decisions that feel good, in the sense of maximizing utility. However, the economic and social norms regarding default are more complicated. Economically, there are several long-term consequences to be considered including the potential cost of relocation, increased cost and/or difficulty in obtaining future credit, possible litigation concerns, and so forth. Emotionally, people generally desire to honor their commitments, and breeching a contract with a lender will likely reduce their reputational capital in the eyes of many within their social network. So while strategic default may appear to represent an initial superficial gain, there are extenuating circumstances that make reasonable people pause before choosing to do so. Thus, widespread use of the inhibition circuitry of the brain makes sense.

This study is the first of its kind to use neurology to understand what is going on inside the human brain while contemplating the strategic mortgage default decision. Better understanding the motivations and considerations taken under advisement by borrowers should help lenders and policymakers remove incentives (financial or emotional) to strategically default. Without this, there is reason to believe the practice will continue to escalate resulting in a continued sluggish economic recovery.

\section{Appendix}

\section{Technical Discussion of the Scientific Methodology}

The scanning was completed using a Siemens 3.0 Tesla Skyra. We acquired high resolution structural scans at a resolution of 1 x 1 x $1 \mathrm{~mm}$. This takes approximately five minutes and merely requires the subjects to lie still. During the experiment we acquired $\mathrm{T} 2 *$-weighted echoplaner images (EPI) in an interleaved manner. ${ }^{15}$ The functional acquisition acquired 40,000 voxels ( $3 \mathrm{~mm} *$ $3 \mathrm{~mm} * 3.5 \mathrm{~mm}$ boxes) of the brain every two seconds for 964 seconds, resulting in 20 million data points for each participant. Functional images were motion corrected with MCFLIRT (Jenkinson, Bannister, Brady, and Smith, 2002), high pass filtered using a width of 100 seconds, and spatially smoothed using a Gaussian kernel with a width of $5 \mathrm{~mm}$.

We constructed the following linear model to estimate across time in each voxel: 


$$
\begin{aligned}
& \text { Activation }_{t}=\text { ModGranted }_{t} \beta_{1}+\text { Conservative }_{t} \beta_{2} \\
& + \text { Egregious }_{t} \beta_{3}+\text { LocalBank }_{t} \beta_{4} \\
& + \text { OnlineBank }_{t} \beta_{5}+\text { DefaultIs Common }_{t} \beta_{6} \\
& + \text { Conservative }^{*} \text { ModGranted }_{t} \beta_{7} \\
& + \text { Egregious }^{*} \text { ModGranted }_{t} \beta_{8} \\
& + \text { LocalBank }^{*} \text { ModGranted } \beta_{9} \\
& + \text { OnlineBank } * \text { ModGranted }_{t} \beta_{10} \\
& + \text { DefaultIsCommon } * \text { ModGranted }_{t} \beta_{11} \\
& + \text { Indicated_Likelihood_of_Default } \beta_{12}+\varepsilon_{t} \text {. }
\end{aligned}
$$

All data are mean centered. The baseline is no modification and default is rare. Because we are interested in the difference between pairs of conditions, we look at, for example, $\beta_{2}-\beta_{3}$ to determine if there is greater activation in a particular voxel for conservative lenders versus egregious lenders. To determine if there is a difference between the effects of modifications on conservative versus egregious lenders, we examine $\beta_{7}-\beta_{8}$.

We create each independent variable with a gamma function having a standard deviation of three seconds and a mean lag of six seconds. The six-second delay is required because this is how long it takes to achieve a hemodynamic response. ${ }^{16}$ The data were pre-whitened using FSL's FILM to correct of autocorrelation (Woolrich, Ripley, Brady, and Smith, 2001). The parameter estimates are then divided by their standard errors resulting in normalized Z-scores allowing them to be compared across different degrees of freedom.

Estimating the linear model across each voxel in the brain results in a set of threedimensional maps of the Z-score at each voxel. We have one full brain map per stimulus (i.e., one per $\beta$ ). We next subtract these maps on a voxel by voxel basis to determine where one stimulus is greater than another. For example, we subtract the activation map for egregious lenders from the activation map for conservative lenders, which results in a map that reveals where egregious lenders have relatively higher Z-scores. We then take the low resolution ( $3 \mathrm{~mm} \times 3 \mathrm{~mm} \times 3.5 \mathrm{~mm}$ ) functional image of the brain and calculate a transformation to map it onto the higher resolution ( $1 \mathrm{~mm} \times 1 \mathrm{~mm} \times 1 \mathrm{~mm})$ map for each subject. This process is carried out through a solid body transform that allows for displacement in three dimensions (up/down, left/right, forward/backward) plus three rotational dimensions.

We next calculate a transformation function to map each subject's individual brain into a high resolution standard brain - the Montreal Neurological Institute's 
MNI152 brain. We use a non-linear registration, FSL's FNIRT to calculate this transform (Andersson, Jenkinson, and Smith, 2007). We then apply both of these transforms to the original functional data to have each subject standardized into the same space. A random effects model is then calculated taking into account "within subject" variability and "between subject" variability to estimate which voxels are significantly different, on average, across the whole group. This procedure is completed using FSL's FLAME, a Bayesian tool (Woolrich et al., 2004).

To correct for multiple comparisons across tens of thousands of regressions, we first remove all Z-scores less than 2.3, leaving only highly significant voxels of activation, and then look for contiguous clusters. Finally, using random field theory, we calculate the probability of a cluster of the size that we actually observe appearing randomly (Worsley, 2001).

\section{Endnotes}

1 The most common reasons for an economic default include loss or curtailment of income, prolonged illness in the family, and death.

${ }^{2}$ Borrowers were only able to correctly identify banks that received bailout funds in $55.04 \%$ (and $52.27 \%$ in a second robustness check sample) of the cases. This percentage is not significantly different from a random coin toss guess.

${ }^{3}$ Seiler (2014) finds that $89.2 \%$ (77.4\% of those in a second, robustness sample) of homeowners studied believe their servicer is the same institution as the underlying owner of the note. Given that Freddie Mac and Fannie Mae own roughly half the mortgages in the country and that they do not service their own loans, any guess over $50 \%$ must be incorrect. Moreover, given that many other owners do not service their own loans, the correct answer is much smaller than $50 \%$.

${ }^{4}$ It is ideal to study the revealed preferences of people as opposed to their stated preferences. However, in many cases, stated preferences are all that can be collected. fMRI technology offers a rare ability to truly measure a revealed preference, and as such, allows us a major insight into this complex decision-making process.

5 The ad we placed simply requested people participate in a study of the housing market. We were intentionally vague in the ad concerning the topic of our investigation so as not to attract any particular subset of the homeowner population. Still, anyone willing to participate in any study may differ from the general population of homeowners in an unknown way. Researchers have no way of testing this possibility, but we still disclose this as a potential drawback to any study that requires volunteers from a population.

${ }^{6}$ Our sample size is also consistent with other studies including Preuschoff, Quartz, and Bossaerts (2008), Bruguier, Quartz, and Bossaerts (2010), Wu, Bossaerts and Knutson (2011), Seiler, Madhavan, and Liechty (2012), and Fryman et al. (2013).

${ }^{7}$ Before the experiment (outside the fMRI machine), participants were explained all relevant real estate/financial terms and even practiced answering a few different hypothetical scenarios to become acquainted with how the system works. Each was given ample time and opportunity to ask questions before we began.

${ }^{8}$ We assume a reasonable amount of amortization given the passage of time. Our figures are consistent with theories and results found in Seiler, Seiler, Traub, and Harrison

\begin{tabular}{l|l|lll} 
J R E R & Vol. 36 & $\mathrm{~N} \circ .3-2014$ \\
\hline
\end{tabular}


(2008), Plaut and Plaut (2010), Zhou and Haurin (2010), Shin, Saginor, and Van Zandt (2011), Zahirovic-Herbert and Chaterjee (2011), Zurada, Levitan, and Guan (2011), MacDonald and Winson-Geideman (2012), and Sun and Seiler (2013).

9 In this study, we intentionally hold constant these variables in order to isolate the impacts of lender characteristics on the decision to strategically default. We fully recognize that the results could vary depending on the several factors we held constant. However, in order to conduct a ceteris paribus analysis, we need to examine lender characteristic variables in isolation. Future studies can examine if these relationships hold under different parameter settings.

${ }^{10}$ One potential weakness of this study is that our experiment involves a hypothetical situation. So while we do use actual homeowners, we have no reason to suspect they are actually going through a strategic mortgage default. As a result, like any experiment, we have no way of confirming the results would necessarily hold when moving from the hypothetical laboratory to the real world. Still, this is a potential drawback to any lab experiment. By using actual homeowners, as opposed to students, we hope to somewhat alleviate this concern.

11 Note that this is not the total time the participant was inside the fMRI because it is also necessary to calibrate the machine to the individual as described in the next section.

12 Seiler (2014) used a between subjects design to test a sample of homeowners across the country, and then as a robustness check, used a within subjects design to perform the same tests on a group of mortgage lenders within a specific area of the country. We use a regional sample of homeowners in a different part of the country. The similarity in results across all three samples indicates a generalizability of the results.

13 In all (but one) remaining exhibit, two-dimensional results are shown in Panel A, while Panel B reveals three-dimensional results.

14 This finding is consistent with Keynes (1965), who concludes that far less utility is derived from being the only one who is right compared with the dis-utility experienced in being the only one who is wrong.

15 We used the following parameters: echo time: $20 \mathrm{~ms}$; field of view: $240 \mathrm{~mm}$; flip angle: $80^{\circ}$ in-plane resolution and slice thickness: $3.5 \mathrm{~mm}$; repetition time: $2000 \mathrm{~ms}$.

16 A hemodynamic response function (HRF) refers to the blood that flows to a part of the brain after a neuron is activated. An HRF is known to be roughly shaped like a gamma function.

\section{References}

An, M. and Z. Qi. Competing Risk Models using Mortgage Duration Data under the Proportional Hazard Assumption. Journal of Real Estate Research, 2012, 34:1, 1-26.

Andersson, J., M. Jenkinson, and S. Smith. Non-linear Registration, aka Spatial Normalisation. FMRIB technical report TR07JA2, 2007.

Boisgueheneuc, F., R. Levy, E. Volle, M. Seassau, H. Duffau, S. Kinkingnehun, Y. Samson, S. Zhang, and B. Dubois. Functions of the Left Superior Frontal Gyrus in Humans: A Lesion Study. Brain, 2006, 129:12, 3315-28.

Bruguier, A., S. Quartz, and P. Bossaerts. Exploring the Nature of Trader Intuition. Journal of Finance, 2010, 65, 1703-23.

Daneshvary, N., T. Clauretie, and A. Kader. Short-Term Own-Price and Spillover Effects of Distressed Residential Properties: The Case of a Housing Crash. Journal of Real Estate Research, 2011, 33:2, 179-206. 
Desmond, J. and G. Glover. Estimating Sample Size in Functional MRI (fMRI) Neuroimaging Studies: Statistical Power Analyses. Journal of Neuroscience Methods, 2002, 118:2, 115-28.

Dimoka, A. How to Conduct a Functional Magnetic Resonance (fMRI) Study in Social Science Research. MIS Quarterly, 2012, 36:3, 811-40.

Ding, L., R. Quercia, W. Li, and J. Ratcliffe. Risky Borrowers or Risky Mortgages Disaggregating Effects Using Propensity Score Models. Journal of Real Estate Research, 2011, 33:2, 245-77.

FICO. Predicting Strategic Default. April, white paper, 2011.

Fryman, C., N. Barberis, C. Camerer, P. Bossaerts, and A. Rangel. Testing Theories of Investor Behavior Using Neural Data. Yale University working paper, 2013.

Gangel, M., M. Seiler, and A. Collins. Exploring the Foreclosure Contagion Effect Using Agent-Based Modeling. Journal of Real Estate Finance and Economics, 2013, 46:2, 33954 .

Guiso, L., P. Sapienza, and L. Zingales. The Determinants of Attitudes towards Strategic Default on Mortgages, Journal of Finance, 2013, 68:4, 1473-1515.

Hampshire, A., S. Chamberlain, M. Montia, J. Duncana, and A. Owena. The Role of the Right Inferior Frontal Gyrus: Inhibition and Attentional Control. NeuroImage, 2010, 50:3, 1313-19.

Jabbi, M., J. Bastiaansen, and C. Keysers. A Common Anterior Insula Representation of Disgust Observation, Experience and Imagination Shows Divergent Functional Connectivity Pathways. PLoS ONE, 2008, 3:8, 1-8.

Jenkinson, M., P. Bannister, J. Brady, and S. Smith. Improved Optimisation for the Robust and Accurate Linear Registration and Motion Correction of Brain Images. NeuroImage, 2002, 17:2, 825-41.

Kadota, H., H. Sekiguchi, S. Takeuchi, M. Miyazaki, Y. Kohno, and Y. Nakajima. The Role of the Dorsolateral Prefrontal Cortex in the Inhibition of Stereotyped Responses. Experimental Brain Research, 2010, 203:3, 593-600.

Keynes, J. The General Theory of Employment, Interest, and Money. New York, NY: Harcourt Brace \& World, 1965.

Liddle, P., K. Kiehl, and A. Smith. Event-Related fMRI Study of Response Inhibition. Human Brain Mapping, 2001, 12, 100-09.

MacDonald, D. and K. Winson-Geideman. Residential Mortgage Selection, Inflation Uncertainty, and Real Payment Tilt. Journal of Real Estate Research, 2012, 34:1, 51-71.

Plaut, O. and S. Plaut. Decisions to Renovate and to Move. Journal of Real Estate Research, 2010, 32:4, 461-84.

Preuschoff, K., S. Quartz, and P. Bossaerts. Human Insula Activation Reflects Risk Prediction Errors as well as Risk. Journal of Neuroscience, 2008, 28, 2745-52.

Rogers, W. and W. Winter. The Impact of Foreclosures on Neighboring Housing Sales. Journal of Real Estate Research, 2009, 31:4, 455-79.

Seiler, M. The Effect of Perceived Lender Characteristics and Market Conditions on Strategic Mortgage Defaults. Journal of Real Estate Finance and Economics, 2014, 48:2, 256-70.

Seiler, M., A. Collins, and N. Fefferman, Strategic Mortgage Default in the Context of a Social Network. Journal of Real Estate Research, 2013, 35:4, 445-76.

\begin{tabular}{l|l|lll} 
J R E R & Vol. 36 & No. $3-2014$ \\
\hline
\end{tabular}


Seiler, M., M. Lane, and D. Harrison. Mimetic Herding Behavior and the Decision to Strategically Default. Journal of Real Estate Finance and Economics, 2014, forthcoming. Seiler, M., P. Madhavan, and M. Liechty. Toward an Understanding of Real Estate Homebuyer Internet Search Behavior: An Application of Ocular Tracking Technology. Journal of Real Estate Research, 2012, 34:2, 211-41.

Seiler, M., V. Seiler, S. Traub, and D. Harrison. Regret Aversion and False Reference Points in Residential Real Estate. Journal of Real Estate Research, 2008, 30:4, 461-74.

Shin, W., J. Saginor, and S. Van Zandt. Evaluating Subdivision Characteristics on SingleFamily Housing Values Using Hierarchical Linear Modeling. Journal of Real Estate Research, 2011, 33:3, 317-48.

Sun, H., and M. Seiler. Hyperbolic Discounting, Reference Dependence and its Implications for the Housing Market. Journal of Real Estate Research, 2013, 35:1, 1-23.

Viard, A., G. Chételat, K. Lebreton, B. Desgranges, B. Landeau, V. Sayette, F. Eustache, and P. Piolino. Mental Time Travel into the Past and the Future in Healthy Aged Adults: An fMRI Study. Brain and Cognition, 2011, 75, 1-9.

Völlm, B., A. Taylor, P. Richardson, R. Corcoran, J. Stirling, S. McKie, J. Deakin, and R. Elliott. Neuronal Correlates of Theory of Mind and Empathy: A Functional Magnetic Resonance Imaging Study in a Nonverbal Task. NeuroImage, 2006, 29:1, 90-8.

Wicker, B., C. Keysers, J. Plailly, J. Royet, V. Gallese, and G. Rizzolatti. Both of Us Disgusted in My Insula: The Common Neural Basis of Seeing and Feeling Disgust. Neuron, 2003, 40:3, 655-64.

Woolrich, M., B. Ripley, J. Brady, and S. Smith. Temporal Autocorrelation in Univariate Linear Modelling of FMRI Data. NeuroImage, 2001, 14:6, 1370-86.

Woolrich, M., T. Behrens, C. Beckmann, M. Jenkinson, and S. Smith. Multi-level Linear Modelling for FMRI Group Analysis Using Bayesian Inference. NeuroImage, 2004, 21:4, 1732-47.

Worsley, K. Statistical Analysis of Activation Images. In: Functional MRI: An Introduction to Methods, P. Jezzard, P.M. Matthews, and S.M. Smith (eds.), OUP, 2001.

$\mathrm{Wu}, \mathrm{C}$., P. Bossaerts, and B. Knutson. The Affective Impact of Financial Skewness on Neural Activity and Choice. PLoS ONE, 2011, 6:2, 1-7.

Wyman, O. Understanding Strategic Default in Mortgages. Experian Report, 2010.

Zahirovic-Herbert, V. and S. Chaterjee. What is the Value of a Name? Conspicuous Consumption and House Prices. Journal of Real Estate Research, 2011, 33:1, 105-25.

Zandbelt, B., T. Gladwin, M. Raemaekers, M. Buuren, S. Neggers, R. Kahn, N. Ramsey, and M. Vink. Within-Subject Variation in BOLD-fMRI Signal Changes Across Repeated Measurements: Quantification and Implications for Sample Size. Neuroimage, 2008, 42:1, 196-206.

Zhou, Y. and D. Haurin. On the Determinants of House Value Volatility. Journal of Real Estate Research, 2010, 32:4, 377-95.

Zurada, J., A. Levitan, and J. Guan. A Comparison of Regression and Artificial Intelligence Methods in a Mass Appraisal Context. Journal of Real Estate Research, 2011, 33:3, 34987.

Michael J. Seiler, The College of William \& Mary, Williamsburg, VA 23187-8795 or Michael.Seiler@mason.wm.edu.

Eric Walden, Texas Tech University, Lubbock, TX 79409 or eric.walden@ttu.edu. 
Copyright of Journal of Real Estate Research is the property of American Real Estate Society and its content may not be copied or emailed to multiple sites or posted to a listserv without the copyright holder's express written permission. However, users may print, download, or email articles for individual use. 